\title{
Shock Wave Speed and Transient Response of PE Pipe with Steel-Mesh Reinforcement
}

\author{
Wuyi Wan $^{1}$ and Xinwei Mao ${ }^{2}$ \\ ${ }^{1}$ Department of Hydraulic Engineering, College of Civil Engineering and Architecture, Zhejiang University, Hangzhou 310058, China \\ ${ }^{2}$ Research and Teaching Labs for Civil and Hydraulic Engineering, College of Civil Engineering and Architecture, \\ Zhejiang University, Hangzhou 310058, China
}

Correspondence should be addressed to Wuyi Wan; wanwuyi@zju.edu.cn

Received 7 December 2015; Revised 1 May 2016; Accepted 5 May 2016

Academic Editor: Tai Thai

Copyright (C) 2016 W. Wan and X. Mao. This is an open access article distributed under the Creative Commons Attribution License, which permits unrestricted use, distribution, and reproduction in any medium, provided the original work is properly cited.

\begin{abstract}
A steel mesh can improve the tensile strength and stability of a polyethylene (PE) pipe in a water supply pipeline system. However, it can also cause more severe water hammer hazard due to increasing wave speed. In order to analyze the influence of the steel mesh on the shock wave speed and transient response processes, an improved wave speed formula is proposed by incorporating the equivalent elastic modulus. A field measurement validates the wave speed formula. Moreover, the transient wave propagation and extreme pressures are simulated and compared by the method of characteristics (MOC) for reinforced PE pipes with various steel-mesh densities. Results show that a steel mesh can significantly increase the shock wave speed in a PE pipe and thus can cause severe peak pressure and hydraulic surges in a water supply pipeline system. The proposed wave speed formula can more reasonably evaluate the wave speed and improve the transient simulation of steel-mesh-reinforced PE pipes.
\end{abstract}

\section{Introduction}

Water hammer events can cause noise, vibration, distortion, and fracture in a water supply pipeline system due to sudden increase or decrease of pressure $[1,2]$. Numerical simulation and prediction are very important to protect the pipeline from undesired damage due to the water hammer effect [3]. It is the fundamental to control the peak transient pressure by optimal operation [4-6], as well as select and design protection devices in water supply pipelines [7]. Furthermore, it is also applicable to some other pipeline transportation areas, such as oil pipelines $[8,9]$ and natural gas pipelines $[10$, 11]. Shock wave speed is a primary factor in various transient simulation models [12-16]. It represents the basic properties of the fluid and pipeline system in transient flow simulations [17]. Usually, wave speed can greatly change the frequency and amplitude of the water hammer waves, as well as the extreme transient pressure distributions along the pipeline [18]. Therefore, the reliability of the result depends heavily on the wave speed in the numerical simulation of the water hammer. Generally, the wave speed is subjected to many factors, such as the density and elastic modulus of the fluid, the material $[19,20]$ and shape of the pipe [21-23], and the means of fixation of the pipe [24]. Moreover, the temperature, pressure, and gas content can also affect the wave speed in a pipe system $[25,26]$. In fact, it is difficult to estimate accurately the shock wave speed. Since the presentation of several basic formulas by Wylie and Streeter [18] for the shock wave speeds, they are widely used in common pipes and conduits. However, it is inapplicable for some specific fluids and composite material pipes, and so some modified approaches have been developed to estimate the shock wave speed for various areas. Sun et al. [24] presented the water hammer speed of fiber-reinforced plastic composite pipes based on three different fixed means. Hachem and Schleiss [27] studied the influence of local wall stiffness decrease on the shock wave speed by experiments, and the result showed the transient pressure change with the wave speed. Han et al. [28] and Zhou et al. [29] studied the shock wave speed of a slurry flow carrying solid particles. Hadj-Taïeb and Lili [30] and Ando et al. [31] studied the shock wave propagation through a deformable tube. Lee and Pejovic [26] studied the influence of air on the similarity of hydraulic transients and vibrations. Soares et al. [22] and Apollonio 
et al. [23] investigated separately the hydraulic transient properties of a pipeline made of plastic material. Mitosek [32] measured the shock wave speed of PVC pipes. Especially for polyethylene pipe, Covas et al. [19, 33, 34] developed a viscoelastic model to take account of the influences of viscoelasticity on transient processes. Evangelista et al. [20] simulated complex plastic pipes system by viscoelastic model and showed that the viscoelasticity needs to be considered in the transient response of a plastic pipe. These previous achievements are significant, but more accurate simulations are required to prevent the water hammer. However, considering the influence of complicated steel-mesh structures, it is presently still difficult to reasonably estimate the wave speed of a large PE pipe with steel-mesh reinforcement. In order to improve the transient simulation of a PE pipe with steel-mesh reinforcement, we propose an improved wave speed formula for reinforced PE pipes by incorporating the equivalent modulus. Also, we conduct a field test to validate the approach. Based on the proposed approach, the transient responses are simulated and compared for PE pipes with various steel-mesh reinforcement ratios. Then the influence of the steel mesh on the transient response is evaluated and discussed. The result shows that the steel mesh can increase the shock wave speed and cause more serve hydraulic surges in the pipeline. The proposed formula is significant to revise the wave speed and improve the transient simulation of steelmesh-reinforced PE pipe.

\section{Basic Shock Wave Speed Formula}

Wave speed can primarily affect the wave propagation and transient pressure, and it is an important parameter for water hammer simulations, as shown in the simplified closed expression equations for water hammer simulation [1]:

$$
\begin{array}{r}
\frac{\partial v}{\partial t}+v \frac{\partial v}{\partial x}+g \frac{\partial h}{\partial x}+\frac{f v|v|}{2 D}=0, \\
\frac{\partial h}{\partial t}+v \frac{\partial h}{\partial x}-v \sin \beta+\frac{a_{0}^{2}}{g} \frac{\partial v}{\partial x}=0 .
\end{array}
$$

For PE pipe, considering the additional viscoelastic term $[20,34]$, the improved continuity equation can be written as

$$
\frac{\partial h}{\partial t}+v \frac{\partial h}{\partial x}-v \sin \beta+\frac{a_{0}^{2}}{\bar{g}} \frac{\partial v}{\partial x}+\frac{2 a_{0}^{2}}{g} \frac{d \varepsilon_{r}}{d t}=0
$$

Generally, the shock wave speed can be determined by Young's modulus of the fluid and the wall material for some regular water supply pipes. Based on basic water hammer equation and mass conservation equations, [1] provided a basic shock wave speed formula:

$$
a_{0}^{2}=\left(\frac{A}{\rho}\right)\left(\frac{d p}{d A}\right) .
$$

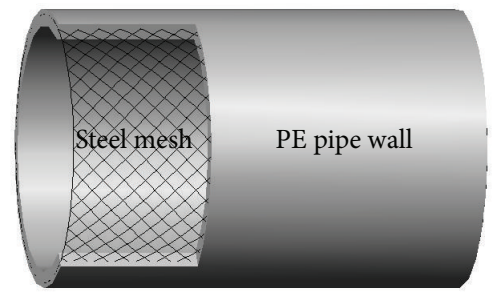

FIGURE 1: Composition of a PE pipe with steel-mesh reinforcement.

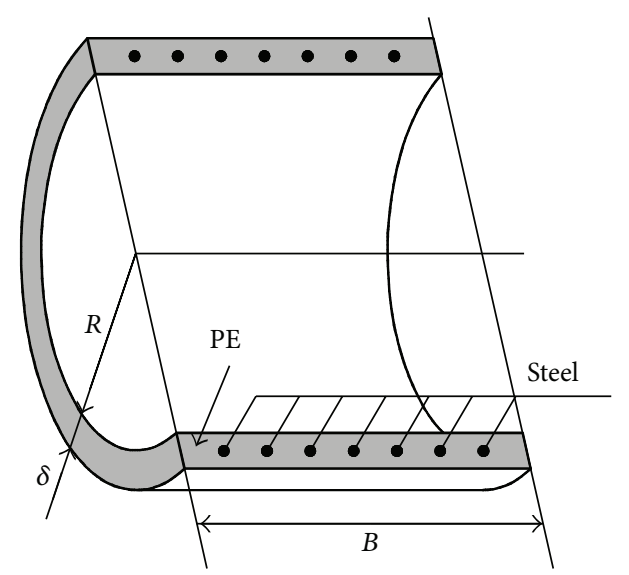

FIGURE 2: Schematic of a steel-mesh-reinforced PE pipe.

For general elastic pipes, the shock wave speed formula can be expressed as [1]

$$
a_{0}=\frac{\sqrt{K / \rho}}{\sqrt{1+\alpha(2 R / \delta)(K / E)}} .
$$

This formula is widely applicable to circular pipes. However, for some complex pipe materials, this formula may need to be improved. As seen in this formula, the modulus of elasticity is an important parameter that determines the wave speed. A reinforced PE pipe has a composite structure, where the steel mesh and polyethylene play different roles. Accordingly, the formula cannot directly determine the wave speed in reinforced PE. Based on the conventional formula, therefore, we will analyze the wave speed for reinforced PE pipe with steel-mesh reinforcement.

\section{Wave Speed Analysis in Reinforced PE Pipes}

3.1. Composition of Steel-Mesh-Reinforced PE Pipe. A general $\mathrm{PE}$ pipe is made of polyethylene. In order to improve the strength, steel meshes are embedded in the pipe wall. Compared to the common $\mathrm{PE}$ pipe, reinforced $\mathrm{PE}$ pipes have more strength and are inflexible. Figures 1 and 2 illustrate the basic structure of a PE pipe with steel-mesh reinforcement. The pipe wall consists of PE and steel meshes. The modulus of the mesh is much larger than that of PE. Thus, the shock wave speed changes greatly with the steel-mesh reinforcement. It is necessary to revise the shock wave speed due to the 


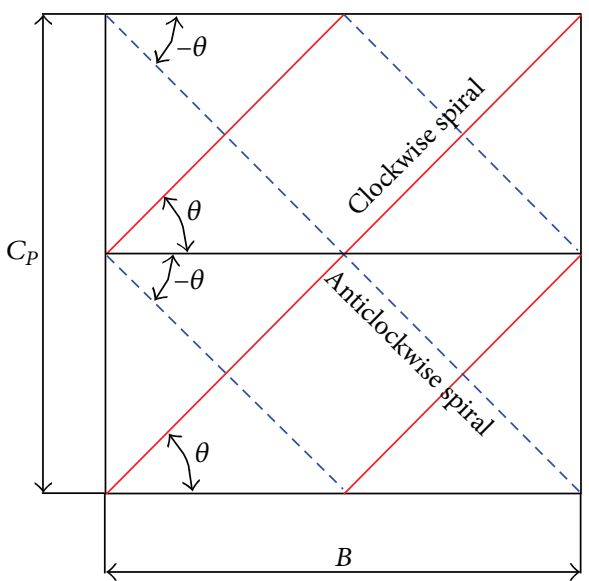

FIGURE 3: Schematic of unfolded pipe wall structure.

steel meshes, in order to obtain a more reasonable transient simulation result.

3.2. Force Analysis of the Pipe Wall under Small Deformation. In order to determine the shock wave speed of a reinforced $\mathrm{PE}$ pipe, an equivalent modulus is proposed for the composite reinforced PE pipe wall. Based on the conventional wave speed formula, the equivalent modulus is used as the modified modulus of pipe wall. In fact, stress and strain occur simultaneously when a pipe is subjected to a water hammer wave. Thus, the transient wave propagation represents the variations of fluid and pipe in pressure and deformation.

Before deriving the equivalent modulus, we will make two assumptions. (1) The deformation is sufficiently small and can be considered as elasticity in instantaneous time, so that the stress and strain can satisfy Hooke's law for both steel meshes and PE. (2) For a finite deformation, there is no relative displacement between the steel thread and the PE material. In other words, steel and PE have the same deformation to bear the extra pressure due to the water hammer pressure.

We select a unit pipe of specific length, around which a steel thread is wound. As shown in Figure 3, the axial length of the pipe is calculated as

$$
\begin{aligned}
B & =C_{P} \cot \theta, \\
C_{P} & =2 \pi(R+0.5 \delta) .
\end{aligned}
$$

Figure 4 shows the unfolded pipe wall. When an internal hydraulic pressure $p$ acts on the pipe wall, the tensile force is equal to the total horizontal component:

$$
P=D B p
$$

In the specific length, a spiral stirrup is considered as an equivalent hoop. For a differential deformation, the total circular force in steel mesh can be expressed as

$$
T_{\mathrm{s}}=2 n A_{\mathrm{s}} \varepsilon E_{\mathrm{s}} \sin \theta \text {. }
$$

Simultaneously, the circular force in the PE material can be expressed as

$$
T_{\mathrm{p}}=2\left(B \delta-\frac{n A_{\mathrm{s}}}{\sin \theta}\right) E_{\mathrm{p}} \varepsilon
$$

3.3. Equivalent Modulus of PE Pipe with Steel-Mesh Reinforcement. Based on the above assumptions, the force of pipe wall can be expressed as

$$
T=2\left[n A_{\mathrm{s}} E_{\mathrm{s}} \varepsilon \sin \theta+\left(B \delta-\frac{n A_{\mathrm{s}}}{\sin \theta}\right) E_{\mathrm{p}} \varepsilon\right] .
$$

If we define an equivalent modulus $E_{\mathrm{e}}$, then the total force can be written as

$$
F_{\mathrm{e}}=2 B \delta E_{\mathrm{e}} \varepsilon
$$

Equations (10) and (11) represent the equal force in magnitude to (7) for an equilibrium state analysis. Accordingly

$$
2 B \delta \varepsilon E_{\mathrm{e}}=2\left[n A_{\mathrm{s}} E_{\mathrm{s}} \varepsilon \sin \theta+\left(B \delta-\frac{n A_{\mathrm{s}}}{\sin \theta}\right) E_{\mathrm{p}} \varepsilon\right] .
$$

Then the equivalent modulus of the pipe wall can be determined as

$$
E_{\mathrm{e}}=\frac{n A_{\mathrm{s}} E_{\mathrm{s}} \sin \theta+\left(B \delta-n A_{\mathrm{s}} / \sin \theta\right) E_{\mathrm{p}}}{B \delta} .
$$

We define the pipe wall reinforcement ratio as

$$
p_{\mathrm{s}}=\frac{n A_{\mathrm{s}}}{B \delta} \text {. }
$$

The reinforcement ratio represents the ratio between the steel areas and the wall section areas. Substituting it into (13), the equivalent elastic modulus can be expressed as

$$
E_{\mathrm{e}}=p_{\mathrm{s}} \sin \theta E_{\mathrm{s}}+\left(1-p_{\mathrm{s}} \csc \theta\right) .
$$

3.4. Improved Wave Speed Formula for a PE Pipe with SteelMesh Reinforcement. Equation (15) provides the equivalent Young's modulus in terms of the reinforcement ratio of the pipe wall. That is to say, we can deal with the reinforced PE pipe wall as a composite material with an equivalent elastic modulus. Accordingly, the wave speed can be expressed as

$$
=\frac{\sqrt{K / \rho}}{\sqrt{1+\alpha(2 R / \delta)\left(K /\left(p_{\mathrm{s}} \sin \theta E_{\mathrm{s}}+\left(1-p_{\mathrm{s}} \csc \theta\right) E_{\mathrm{p}}\right)\right)}} .
$$

Provided we know the number and winding angle of the spiral steel wire in pipe cross section, the improved formula can calculate the shock wave speed for a PE pipe with steelmesh reinforcement. 
TABLE 1: Comparison of test and calculation.

\begin{tabular}{lccccccccc}
\hline$R(\mathrm{~mm})$ & $\delta(\mathrm{mm})$ & $p_{\mathrm{s}}(\%)$ & $\theta$ & $E_{\mathrm{p}}(\mathrm{GPa})$ & $E_{\mathrm{s}}(\mathrm{GPa})$ & $E_{\mathrm{e}}(\mathrm{GPa})$ & $a_{\mathrm{n}}(\mathrm{m} / \mathrm{s})$ & $a_{\mathrm{m}}(\mathrm{m} / \mathrm{s})$ & $\varepsilon_{a}$ \\
\hline 232 & 18 & $1.48 \%$ & $42.26^{\circ}$ & 1.43 & 207 & 3.43 & 385.0 & 379.8 & $1.37 \%$ \\
\hline
\end{tabular}

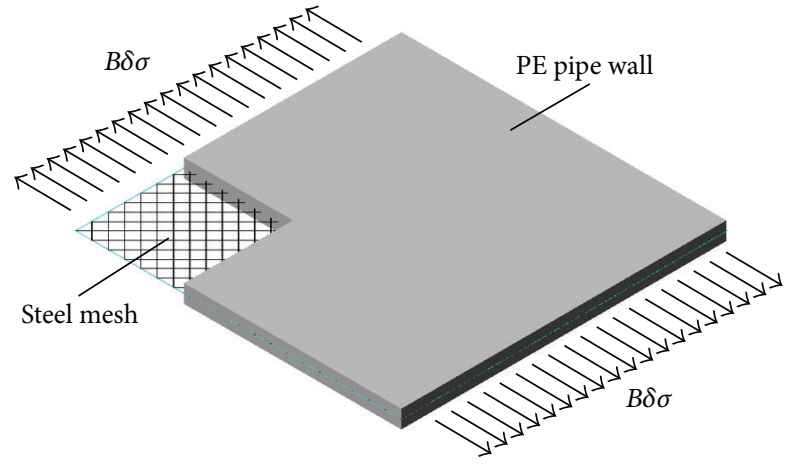

FIGURE 4: Force analysis of the unfolded pipe wall.

3.5. Validation of the Wave Speed Formula. In fact, it is difficult to conduct an experiment to obtain the shock wave speed for a large PE pipe with steel-mesh reinforcement in the field. Fortunately, a practical project supports the field to validate the proposed formula. As a result, the experiment is subject to the practical scale and layout of the project. Figure 5 shows the schematic of pipeline and stations in the field test, where $s_{1}$ is a $20.16 \mathrm{~km}$ PE pipe, $s_{2}$ is a $0.4 \mathrm{~km}$ steel pipe, and $s_{3}$ is a $0.1 \mathrm{~km}$ steel pipe. Moreover, the PE pipe is $0.232 \mathrm{~m}$ in internal radius and $0.018 \mathrm{~m}$ in thickness.

In the experiment, the control valve will give rise to a negative pressure wave by sudden opening and discharging water from the main pipe at initial time $t_{0}$, and then the negative wave propagates along the pipe to the stations. Stations 1 and 2 detect the wave at times $t_{1}$ and $t_{2}$, respectively. According to the time and wave speed, the following equations can be written:

$$
\begin{array}{r}
\frac{s_{1}}{a_{\mathrm{p}}}+\frac{s_{2}}{a_{\mathrm{s}}}=t_{1}-t_{0}, \\
\frac{s_{1}}{a_{\mathrm{p}}}+\frac{s_{2}}{a_{\mathrm{s}}}+\frac{s_{3}}{a_{\mathrm{s}}}=t_{2}-t_{0} .
\end{array}
$$

According to $t_{0}, t_{1}$, and $t_{2}$, the experimental wave speed can be obtained as follows:

$$
a_{\mathrm{p}}=\frac{s_{1} s_{3}}{\left(t_{1}-t_{0}\right)\left(s_{2}+s_{3}\right)-\left(t_{2}-t_{0}\right) s_{2}} .
$$

Figure 6 shows the pressure response at station 1 and station 2, respectively. The beginning time of the impulse $t_{0}$ is $29.61 \mathrm{~s}$, and the response times $t_{1}$ and $t_{2}$ are, respectively, 83.109 and $83.214 \mathrm{~s}$ at station 1 and station 2. According to (19), the experimental wave speed can be obtained.

As shown in Table 1, the experimental wave speed is $379.8 \mathrm{~m} / \mathrm{s}$. According to the steel-mesh density and winding angle of the spiral steel wire, the proposed theoretical formula yields a collective wave speed $385.0 \mathrm{~m} / \mathrm{s}$. The error is about $1.37 \%$. The comparison shows that the computational result agrees well with the measurement. The proposed formula can provide a reasonable result for the PE pipe with steel-mesh reinforcement.

3.6. Influence of Reinforcement Ratio on Wave Speeds of a PE Pipe. As is well known, the elastic modulus can greatly affect the shock wave speed. Since the reinforcement can primarily affect the elastic modulus, it can also change the shock wave speed. Next, the influence of the steel-mesh density on the wave speed is studied, including the reinforcement ratios and winding angles. Based on the proposed formula, Figure 7 shows the influence of the reinforcement ratio on shock wave speed for three different PE pipe walls. For a given pipe diameter, wall thickness, and winding angle of the steel wire, the wave speed increases with the reinforcement ratio. If we define reinforcement ratio as 0 , it will indicate actually the original PE material pipe without steel meshes, and the wave speed is only about $250 \mathrm{~m} / \mathrm{s}$. Obviously, the wave speed increases with the reinforcement ratio. Moreover, for a given diameter, wall thickness, and reinforcement ratio, the wave speed also increases with the winding angle of steel wire, as shown in Figure 8. In fact, for a specified reinforcement ratio in the section, the density of the steel mesh increases with the winding angle along the axial direction. It shows that the wave speed changes because of the steel mesh enhancing the elastic modulus of the $\mathrm{PE}$ pipe. In practice, the range of the reinforcement ratio is $1 \%-2 \%$, and the winding angle of a rhombic metal mesh is about $42.26^{\circ}$; accordingly, the wave speed in the PE pipe may increase to $300-400 \mathrm{~m} / \mathrm{s}$.

\section{Effects of Steel Mesh on Transient Responses of the PE Pipe}

4.1. Selection of Transient Simulation Model. Considering the viscoelasticity of PE materials, the viscoelastic model is needed to simulate the hydraulic transient processes. Covas et al. [34] developed a conventional viscoelastic model, and the model is also well verified in complex plastic pipes system [20]. Given the wave speed, (1) and (3) form a closed system for the water hammer simulations. Considering the viscoelastic model [34] and coupling the method of characteristics [1], the modified MOC equation systems can be expressed as

$$
\begin{gathered}
\frac{g}{a_{0}} \frac{d h}{d t}+\frac{d v}{d t}+\frac{f v|v|}{2 D}+2 a_{0}\left(\frac{\partial \varepsilon_{r}}{\partial t}\right)=\left.0\right|_{d x / d t=+a_{0}}, \\
-\frac{g}{a_{0}} \frac{d h}{d t}+\frac{d v}{d t}+\frac{f v|v|}{2 D}+2 a_{0}\left(\frac{\partial \varepsilon_{r}}{\partial t}\right)=\left.0\right|_{d x / d t=-a_{0}} .
\end{gathered}
$$




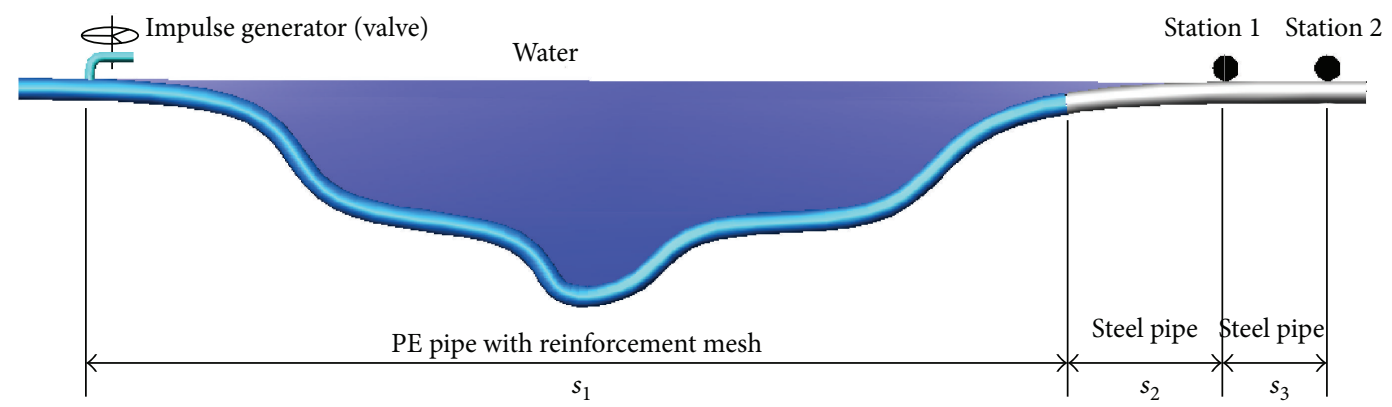

FIGURE 5: Schematic of wave speed measurement in the field.

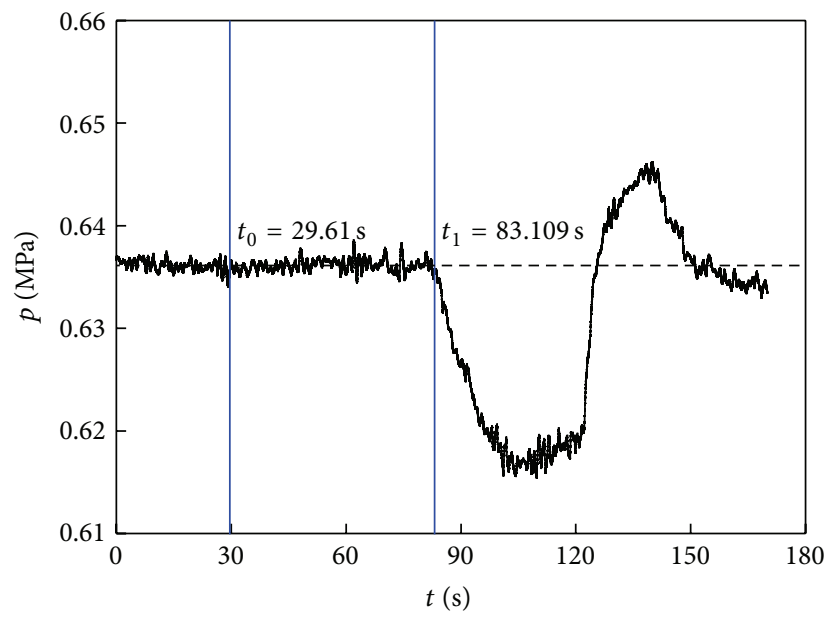

Station 1

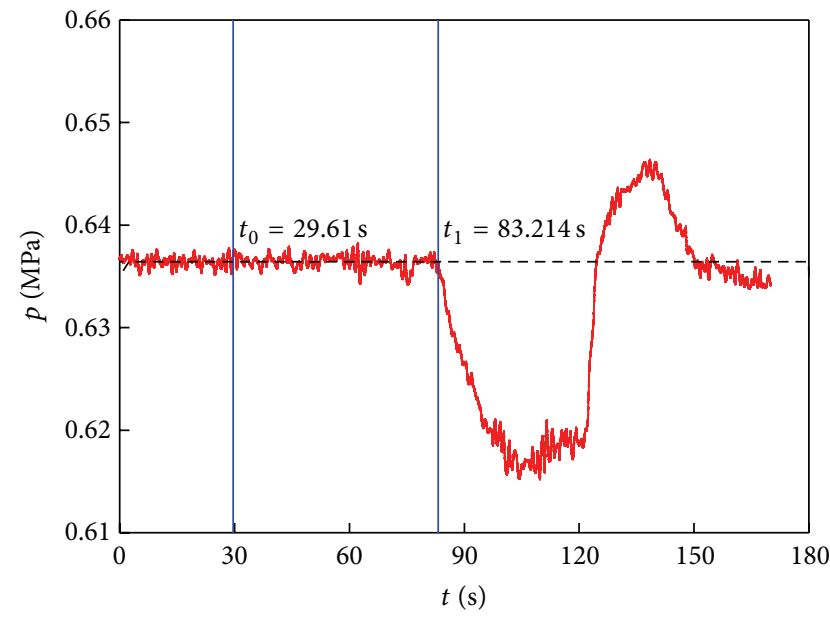

Station 2

FIgURE 6: Pressure surge in the stations.

Integral along the characteristic line, the system of equations can be converted as

$$
\begin{aligned}
& h_{i, t+\Delta t}+\frac{a_{0}}{g} v_{i, t+\Delta t}+2 \frac{a_{0}^{2} \Delta t}{g}\left(\frac{\partial \varepsilon_{r}}{\partial t}\right)-C_{F}=0, \\
& h_{i, t+\Delta t}-\frac{a_{0}}{g} v_{i, t+\Delta t}+2 \frac{a_{0}^{2} \Delta t}{g}\left(\frac{\partial \varepsilon_{r}}{\partial t}\right)-C_{R}=0 .
\end{aligned}
$$

In the equations, $C_{F}=h_{i-1, t}+v_{i-1, t} a_{0} / g-\operatorname{sgn}(v) f \Delta x v_{i-1, t}^{2} /$ $(2 g D)$ and $C_{R}=h_{i+1, t}-v_{i+1, t} a_{0} / g+\operatorname{sgn}(v) f \Delta x v_{i+1, t}^{2} /(2 g D)$.

About the term $\partial \varepsilon_{r} / \partial t$, Covas et al. [34] have proposed an applied model. According to the model, the term can be expressed as

$$
\frac{\partial \varepsilon_{r}(i, t+\Delta t)}{\partial t}=C_{S} h_{i, t+\Delta t}+C_{T}
$$

where $C_{S}=\left(\alpha \rho a_{0}^{2} D / \delta\right) \sum_{k=1}^{n} J_{k}\left(1-e_{k}\right), e_{k}=e^{-\Delta t / \tau_{k}}, C_{T}=$ $2\left(a_{0}^{2} \Delta t / g\right) \sum_{k=1}^{n}\left\{\left(J_{k} e_{k} / \tau_{k}\right)(\alpha D / 2 \delta)\left(h_{i, t}-h_{i, 0}\right)-\left(J_{k}(1-\right.\right.$ $\left.\left.\left.e_{k}\right) / \Delta t\right)(\alpha D / 2 \delta) \rho g h_{i, t}-e_{k} \widetilde{\varepsilon}_{r k(i, t)}\right\}, F_{i, t}=(\alpha D / 2 \delta) \rho g\left[h_{i, t}-\right.$ $\left.h_{i, 0}\right]$, and $\widetilde{\varepsilon}_{r k(i, t)}=J_{k} F_{i, t}-J_{k} e_{k} F_{i, t-\Delta t}-\left(J_{k} \tau_{k}\left(1-e_{k}\right) / \Delta t\right)\left(F_{i, t}-\right.$ $\left.F_{i, t-\Delta t}\right)+e_{k} \widetilde{\varepsilon}_{r k(i, t-\Delta t)}$.
For a present step, all values at initial time $t$ are known. A system of closed equations is obtained. Then the solution of the simultaneous equations can be written as

$$
\begin{aligned}
h_{i, t+\Delta t} & =\frac{0.5\left(C_{F}+C_{R}+2 C_{T}\right)}{\left(1+C_{S}\right)}, \\
v_{i, t+\Delta t} & =\frac{\left(h_{i, t+\Delta t}+C_{S}+C_{T}-C_{R}\right) g}{a_{0}} .
\end{aligned}
$$

To simulate the transient process with viscoelastic properties, a six-element Kelvin-Voigt model and basic creep functions of polyethylene [34] are adopted. In order to analyze the influence of the elastic steel mesh, an extra spring is added. Figure 9 shows the improved six-element Kelvin-Voigt model. In the model, the instantaneous elastic is modified to the compound of the PE instantaneous elastic and the steel instantaneous elastic according to their contribution factors. In the figure, $E_{\mathrm{es}}=p_{\mathrm{s}} \sin \theta E_{\mathrm{s}}$ and $E_{\mathrm{ep}}=\left(1-p_{\mathrm{s}} \csc \theta\right) E_{\mathrm{p}} \approx E_{\mathrm{p}}$.

For viscoelastic solid, the basic Kelvin-Voigt creep function can be written as [35]

$$
J(t)=J_{0}+\sum_{k=1}^{N} J_{k}\left(1-e^{-t / \tau_{k}}\right) .
$$




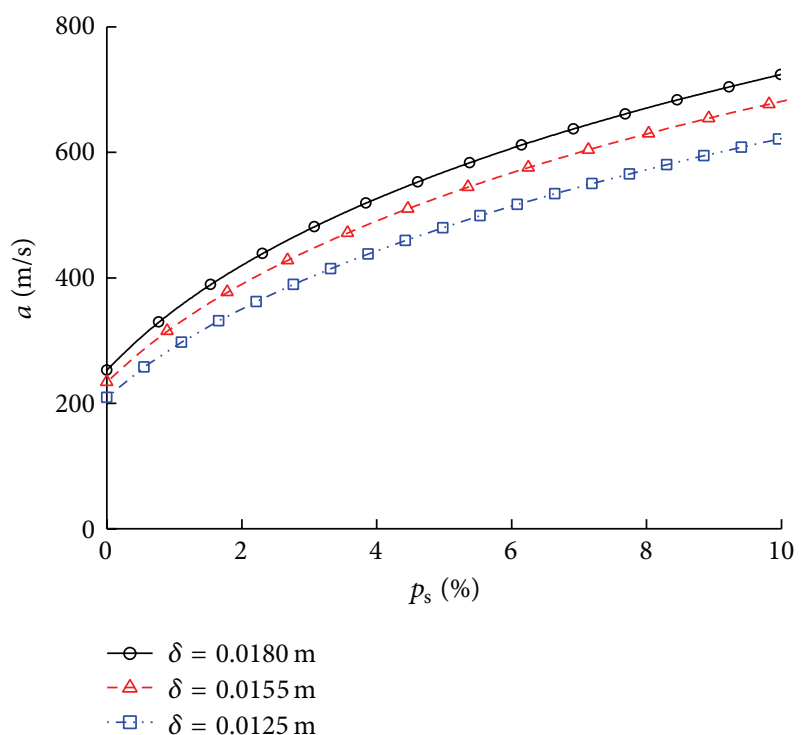

FIGURE 7: Influence of reinforcement ratio on the wave speed.

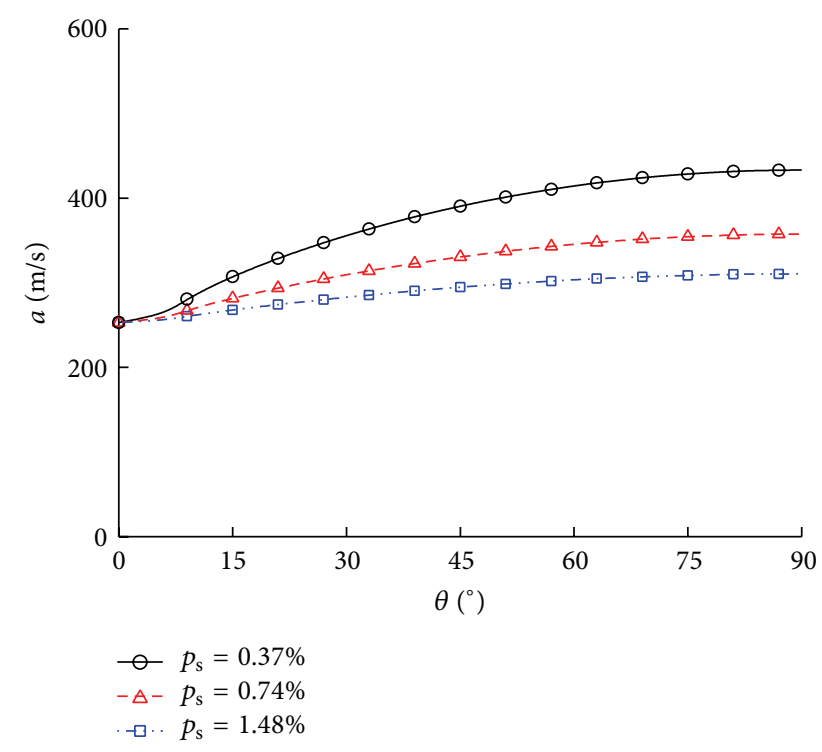

FIGURE 8: Influence of spiral winding angle on the wave speed.

Covas et al. [34] have fixed several creep functions for typical polyethylene materials. In order to describe the behavior of the polyethylene, especially, the basic creep coefficient is approximated by the six-element Kelvin-Voigt model [34], which has the corresponding instantaneous creep compliance $J_{0}=0.7 \times 10^{-9} \mathrm{~Pa}^{-1}$. For PE pipe with steel mesh, the improved model is modified to $J_{0}=1 /\left(E_{\mathrm{ep}}+E_{\mathrm{es}}\right)$, as shown in Figure 9. Considering the influence of the steel mesh, Figure 10 shows the modified creep functions for different reinforcement ratios.

4.2. Pipe and Material Parameters. As shown in the previous section, the steel mesh can greatly increase the shock wave speed; meanwhile, it can also cause more severe transient

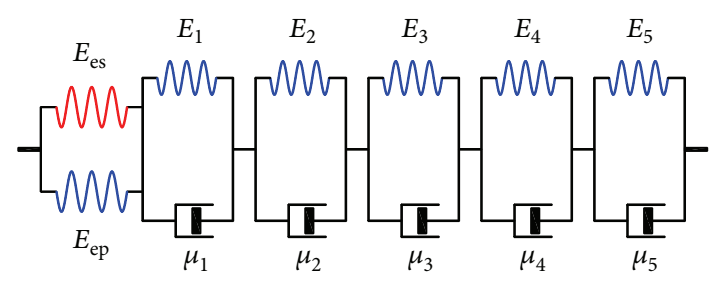

FIGURE 9: Six-element Kelvin-Voigt viscoelastic model with steel mesh.

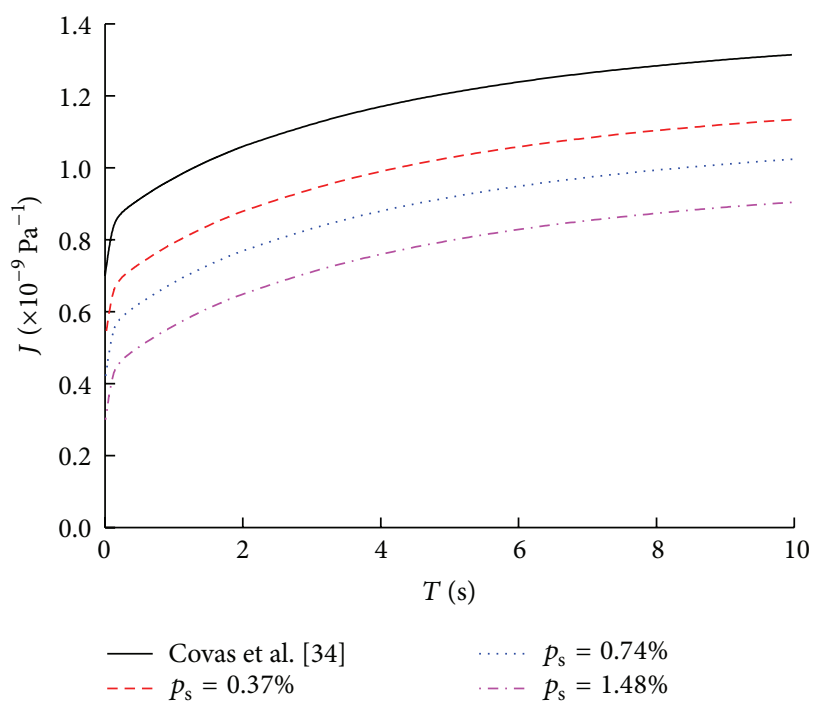

FIgURE 10: Modified creep function for PE pipe with steel mesh.

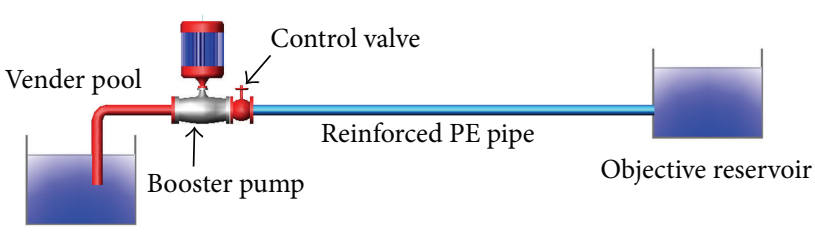

Figure 11: Basic model of a water supply PE pipe system.

pressure. In order to analyze the influence of the steel mesh on the transient response, various reinforcement ratios are considered in the same scale pipeline system. As shown in Figure 11, the system is composed of a booster pump, a control valve, the main pipe, and the downstream reservoir. In the example, the pipe is $0.5 \mathrm{~m}$ in external diameter, $0.018 \mathrm{~m}$ in wall thickness, and $2500 \mathrm{~m}$ in length. Four types of reinforcements are simulated to analyze the influence of the steel mesh on the transient response. The reinforcement ratios are $0 \%$ (the pure PE materials), $0.37 \%, 0.74 \%$, and $1.48 \%$ separately. Table 2 shows the equivalent elastic modulus and shock wave speed parameters for next transient simulation according to the proposed method.

\subsection{Influence of Steel-Mesh Reinforcement on Transient} Response of PE Pipe. In the example, the hydraulic transients of pump failure were numerically simulated and compared for the water supply system. Figure 12 compares the transient 
TABLE 2: Wave speeds of PE pipes with various reinforcement ratios.

\begin{tabular}{lcccccccc}
\hline PE & $R(\mathrm{~mm})$ & $\delta(\mathrm{mm})$ & $p_{\mathrm{s}}(\%)$ & $\theta\left(^{\circ}\right)$ & $E_{\mathrm{p}}(\mathrm{GPa})$ & $E_{\mathrm{s}}(\mathrm{GPa})$ & $E_{\mathrm{e}}(\mathrm{GPa})$ & $a_{0}(\mathrm{~m} / \mathrm{s})$ \\
\hline$\Phi 500$ & 232 & 18 & 0.00 & - & 1.43 & 207 & 2.43 \\
$\Phi 500$ & 232 & 18 & 0.37 & 42.26 & 1.43 & 207 & 1.94 \\
$\Phi 500$ & 232 & 18 & 0.74 & 42.26 & 1.43 & 207 & 2.04 \\
$\Phi 500$ & 232 & 18 & 1.48 & 42.26 & 1.43 & 207 & 3.82 \\
\hline
\end{tabular}
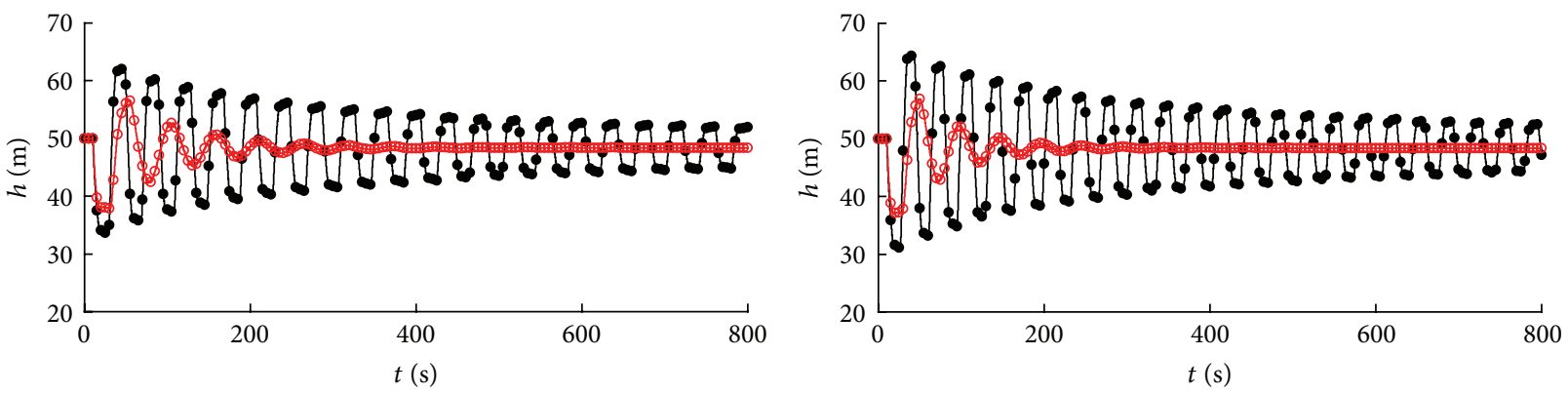

Without steel mesh

- Classic model

- Viscoelastic model
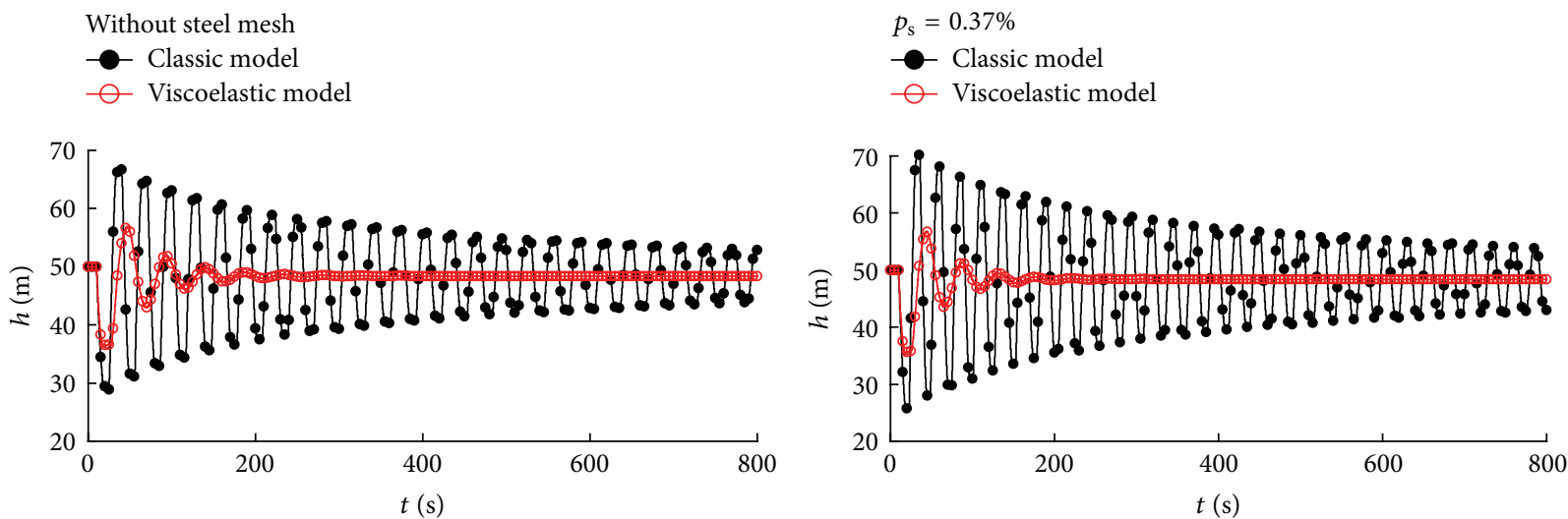

$p_{\mathrm{s}}=0.74 \%$

$p_{\mathrm{s}}=1.48 \%$

- Classic model

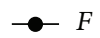

- Classic model
- Viscoelastic model

$\checkmark$ Viscoelastic model $\quad-F$

FIGURE 12: Comparison of pressure waves by different transient models.

response by the classic model and the viscoelastic model. The result shows that viscoelasticity has a great effect on transient process; it needs to take account of viscoelasticity in transient simulation of PE pipe with steel mesh. Figure 13 shows the transient pressure waves of the same scale $\mathrm{PE}$ pipe with different reinforcement ratios. As seen in the figure, the negative pressure is the largest when the $\mathrm{PE}$ pipe has the reinforcement ratio of $1.48 \%$. Conversely, the negative pressure is the least for the $\mathrm{PE}$ pipe without the steel mesh. Obviously, the transient intensities increase with the reinforcement ratio, as well as the wave frequency and amplitude. Accordingly, Figure 14 shows the distribution of extreme transient pressure along the pipeline. Compared with the original extreme pressures, Table 3 shows that the steel-mesh reinforcement has increased the amplitudes of the transient pressure along the entire pipeline.
TABLE 3: Extreme pressure with various reinforcement ratios (viscoelastic model).

\begin{tabular}{lccccc}
\hline$p_{\mathrm{s}}(\%)$ & $a(\mathrm{~m} / \mathrm{s})$ & $h_{0}(\mathrm{~m})$ & $h_{\min }(\mathrm{m})$ & $h_{\max }(\mathrm{m})$ & $A_{\mathrm{m}}(\mathrm{m})$ \\
\hline 0.00 & 253.04 & 49.95 & 37.84 & 56.75 & 12.11 \\
0.37 & 292.82 & 49.95 & 36.88 & 56.91 & 13.07 \\
0.74 & 327.10 & 49.95 & 36.16 & 56.92 & 13.79 \\
1.48 & 384.95 & 49.95 & 35.20 & 56.78 & 14.75 \\
\hline
\end{tabular}

Figure 15 shows the changes of the extreme pressures and amplitudes with the reinforcement ratio. As seen in this figure, the pressure surge increases with the reinforcement ratio. The result shows that steel-mesh reinforcement can cause more severe transient response due to increase in the shock wave speed of the PE pipes. Therefore, the modified wave speed formula and viscoelastic model can improve 


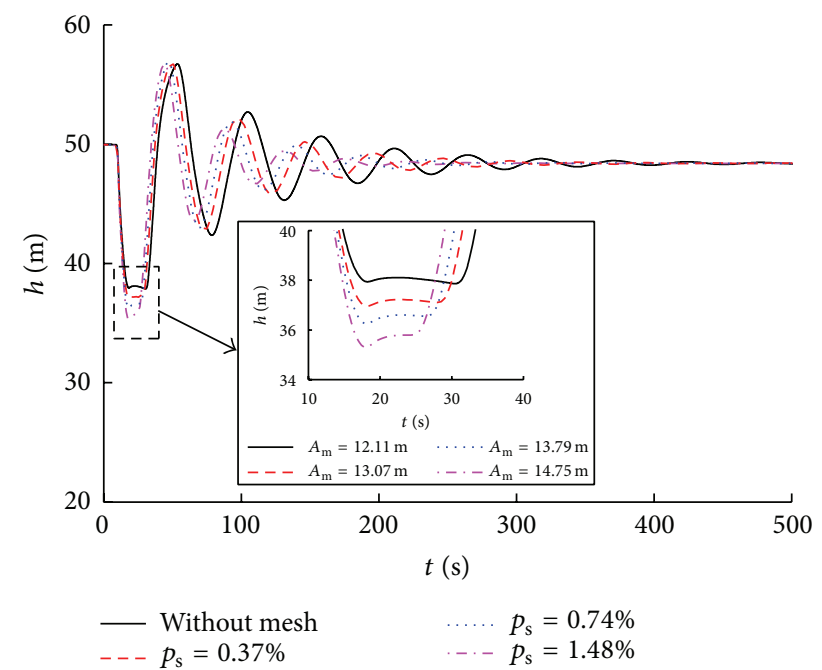

FIGURE 13: Pressure waves for various reinforcement ratios.

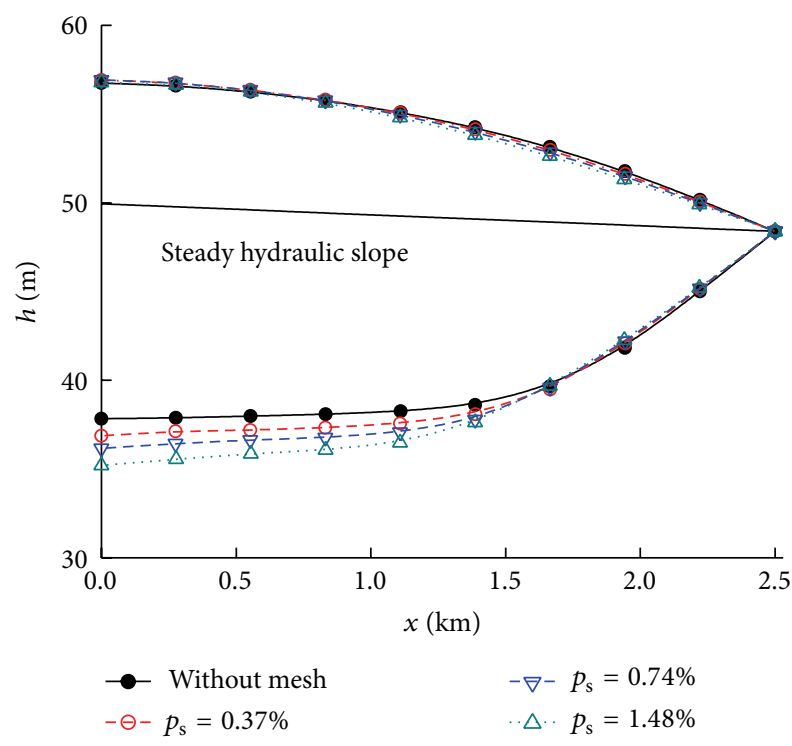

FIGURE 14: Extreme pressure distributions along the pipeline.

the transient simulation of the PE pipe with steel-mesh reinforcement for a water supply system.

\section{Discussion}

For the composite structure of a PE pipe with steel-mesh reinforcement, an equivalent instantaneous elastic modulus is used to determine the water hammer properties of the reinforced system. Then an improved shock wave speed formula is proposed for the reinforced PE pipe based on the reinforcement ratios and winding angles of spiral steel threads. Accordingly, the formula is validated by a field measurement in a submarine PE pipe with steel-mesh reinforcement. Finally, transient simulation is applied to analyze the influence of the steel mesh on the hydraulic transients of the reinforced PE pipe. Compared to the original uniform PE material, the steel-mesh-reinforced PE material has a higher

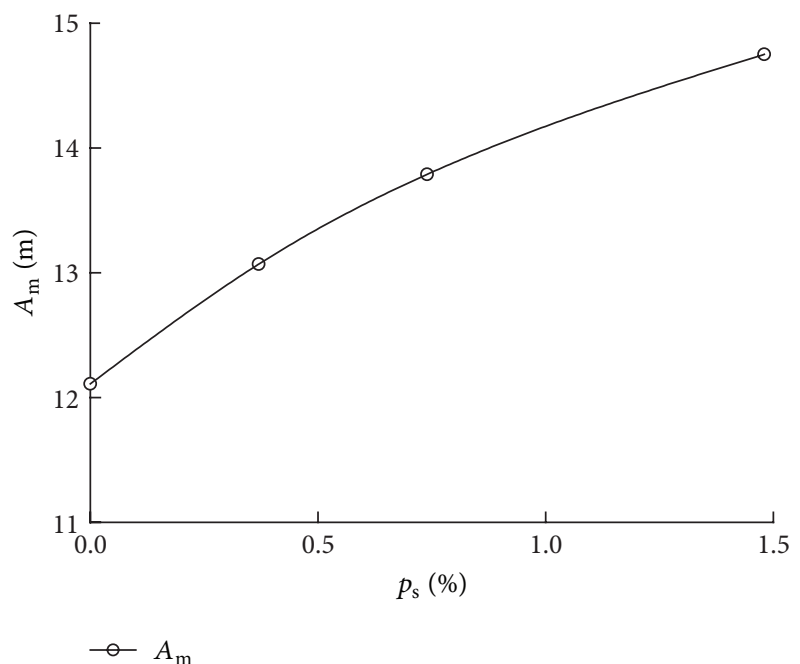

FIGURE 15: Transient intensions for various reinforcement ratios.

elastic modulus and a larger shock wave speed. Therefore, it can cause more severe transient pressure. For example, the negative pressure, wave amplitudes, and frequencies greatly increase with the steel-mesh reinforcement ratio. Viscoelastic model especially is needed to take account of the viscoelasticity of the PE pipe. Obviously, a higher wave speed increases the water hammer risks due to the steelmesh reinforcement in a PE pipe. It is necessary to evaluate the water hammer pressure more seriously because of the effects of the steel mesh in PE pipe system. The viscoelastic model and the proposed shock wave speed can yield a more reasonable transient simulation in the PE pipe with steelmesh reinforcement.

\section{Conclusion}

A steel mesh can greatly affect the transient intensity in a PE pipe water supply system, because it increases the shock wave speed in the PE pipe. Generally, a steel mesh can cause more serious water hammer peak pressure and hydraulic fluctuation; thus more consideration on the reinforcement mesh is necessary to protect the pipeline from water hammer damage. It is worth reevaluating the shock wave speed according to the density and winding angle of the steel mesh. The equivalent elastic modulus is presented to indicate the material properties of steel-mesh-reinforced PE pipe wall. Accordingly, an improved wave speed formula is proposed to evaluate reasonably the water hammer speed for the reinforced PE pipe. It agrees well with a field measurement in a submarine reinforced PE pipeline system. Given the reinforcement ratio and winding angle of the spiral steel threads, the improved formula can conveniently be applied to the calculation of water hammer speed. Moreover, viscoelasticity has a great effect on transient process; it needs to take account of viscoelasticity in transient simulation of PE pipe with steel mesh. The comparison of various reinforcement ratios shows that the steel mesh can increase the transient pressure, as 
well as the wave frequency and amplitude. Consequently, it is significant to evaluate reasonably the wave speed by the proposed formula and improve the transient simulation by viscoelastic model for water hammer prediction and prevention in a reinforced PE pipe system.

\section{Nomenclature}

$a_{\mathrm{m}}: \quad$ Measured water hammer speed $(\mathrm{m} / \mathrm{s})$

$a_{\mathrm{n}}$ : Calculated water hammer speed $(\mathrm{m} / \mathrm{s})$

$a_{\mathrm{p}}$ : Wave speed of PE pipe in field test $(\mathrm{m} / \mathrm{s})$

$a_{s}: \quad$ Wave speed of steel pipe in field test $(\mathrm{m} / \mathrm{s})$

$a_{0}$ : Wave speed of water hammer $(\mathrm{m} / \mathrm{s})$

$A$ : Internal section area of pipe $\left(\mathrm{m}^{2}\right)$

$A_{\mathrm{m}}:$ Maximum amplitude of pressure surge (m)

$A_{\mathrm{s}}$ : Section area of the steel wire $\left(\mathrm{m}^{2}\right)$

$B: \quad$ Length of the unit pipe $(\mathrm{m})$

$C_{P}:$ Mean perimeter of pipe wall $(\mathrm{m})$

$C_{F}:$ Specified aggregative variable

$C_{R}$ : Specified aggregative variable

$C_{S}$ : Specified aggregative variable

$C_{T}$ : Specified aggregative variable

$D: \quad$ Internal diameter of pipe $(\mathrm{m})$

$e_{k}$ : Specified dependent variable

$E: \quad$ Young's modulus of pipe materials $(\mathrm{Pa})$

$E_{\mathrm{e}}: \quad$ Equivalent modulus of pipe wall $(\mathrm{Pa})$

$E_{\mathrm{ep}}:$ Instantaneous bulk modulus of $\mathrm{PE}$ materials $(\mathrm{Pa})$

$E_{\text {es }}: \quad$ Equivalent bulk modulus of steel $(\mathrm{Pa})$

$E_{\mathrm{p}}$ : Young's modulus of $\mathrm{PE}$ materials $(\mathrm{Pa})$

$E_{\mathrm{s}}: \quad$ Modulus of steel $(\mathrm{Pa})$

$f:$ Darcy-Weisbach friction factor

$F_{\mathrm{e}}$ : $\quad$ Equivalent circumferential force in per unit length pipe wall $(\mathrm{N})$

$g: \quad$ Acceleration of gravity $\left(\mathrm{m} / \mathrm{s}^{2}\right)$

$h$ : Pressure head (m)

$h_{\max }:$ Maximum water hammer pressure head (m)

$h_{\text {min }}$ : Minimum water hammer pressure head (m)

$i: \quad$ Serial number of nodes (s)

$J_{k}$ : Creep of the springs in Kelvin-Voigt model $\left(\mathrm{Pa}^{-1}\right)$

$K: \quad$ Young's modulus of fluid $(\mathrm{Pa})$

$n: \quad$ Number of steel lines in specific length pipe wall

$N$ : Number of elements in Kelvin-Voigt model

$p: \quad$ Pressure in internal side of the pipe $(\mathrm{Pa})$

$p_{s}: \quad$ Reinforcement ratio of pipe wall

$P: \quad$ Horizontal force in unit length $(\mathrm{N})$

$r_{\mathrm{s}}: \quad$ Radius of the steel wire $(\mathrm{m})$

$R: \quad$ Internal radius of the pipe $(\mathrm{m})$

$s_{1}$ : $\quad$ Length of PE pipe (m)

$s_{2}: \quad$ Length of steel pipe $(\mathrm{m})$

$s_{3}: \quad$ Distance between stations (m)

$t: \quad$ Time, as subscript to denote time (s)

$t_{0}$ : Beginning time of impulse (s) $t_{1}:$ Initial response time in the first station (s)

$t_{2}$ : Initial response time in the second station (s)

$T_{\mathrm{p}}$ : Circular tensile on PE pipe wall $(\mathrm{N})$

$T$ : Circumferential tensile force in unit length pipe wall $(\mathrm{N})$

$T_{\mathrm{s}}$ : Circular tensile on steel wire $(\mathrm{N})$

v: Flow velocity $(\mathrm{m} / \mathrm{s})$

$x$ : Distance from inlet $(\mathrm{m})$

$\alpha$ : Dimensionless constant of pipe constraint conditions

$\beta$ : $\quad$ Pipe slope (rad)

$\theta: \quad$ Winding angle of spiral steel wire $(\mathrm{rad})$

$\delta: \quad$ Thickness of the pipe wall $(\mathrm{m})$

$\varepsilon: \quad$ Circumferential strain of pipe wall $(\mathrm{m} / \mathrm{m})$

$\varepsilon_{a}:$ Error between calculation and measurement

$\varepsilon_{r}:$ Retarded strain $(\mathrm{m} / \mathrm{m})$

$\widetilde{\varepsilon}_{r k}:$ Strain in initial time $(\mathrm{m} / \mathrm{m})$

$\rho: \quad$ Density of fluid $\left(\mathrm{kg} / \mathrm{m}^{3}\right)$

$\sigma: \quad$ Stress in pipe wall $(\mathrm{Pa})$

$\tau_{k}$ : Retardation time of dashpots (s)

$\mu_{k}$ : Viscosity of the dashpots $(\mathrm{kg} / \mathrm{sm})$

$\Delta t$ : Time step (s)

$\Delta x$ : Step of segment $(\mathrm{m})$.

Acronyms

MOC: Method of characteristics

PE: Polyethylene.

\section{Competing Interests}

The authors declare that they have no competing interests.

\section{Acknowledgments}

This work was supported by the National Natural Science Foundation of China (Grant no. 51279175), the Zhejiang Provincial Natural Science Foundation of China (Grant no. LZ16E090001), and the Open Foundation of the State Key Laboratory of Hydraulic Engineering Simulation and Safety, Tianjin University (HESS-1505).

\section{References}

[1] E. B. Wylie, V. L. Streeter, and L. Suo, Fluid Transients in Systems, Prentice Hall, Englewood Cliffs, NJ, USA, 1993.

[2] M. Chaudhry, Applied Hydraulic Transients, Van Nostrana Reinhold, New York, NY, USA, 1987.

[3] D. J. Wood, "Waterhammer analysis-essential and easy (and efficient)," Journal of Environmental Engineering (ASCE), vol. 131, no. 8, pp. 1123-1131, 2005.

[4] M. R. Bazargan-Lari, R. Kerachian, H. Afshar, and S. N. BashiAzghadi, "Developing an optimal valve closing rule curve for real-time pressure control in pipes," Journal of Mechanical Science and Technology, vol. 27, no. 1, pp. 215-225, 2013. 
[5] W. Wan and W. Huang, "Investigation of fluid transients in centrifugal pump integrated system with multi-channel pressure vessel," Transactions of the ASME Journal of Pressure Vessel Technology, vol. 135, no. 6, Article ID 061301, 2013.

[6] W. Y. Wan, W. R. Huang, and C. Li, "Sensitivity analysis for the resistance on the performance of a pressure vessel for water hammer protection," Journal of Pressure Vessel TechnologyTransactions of the ASME, vol. 136, no. 1, Article ID 011303, 2014.

[7] S.-H. Kim, "Design of surge tank for water supply systems using the impulse response method with the GA algorithm," Journal of Mechanical Science and Technology, vol. 24, no. 2, pp. 629-636, 2010.

[8] F. Esmaeilzadeh, D. Mowla, and M. Asemani, "Mathematical modeling and simulation of pigging operation in gas and liquid pipelines," Journal of Petroleum Science and Engineering, vol. 69, no. 1-2, pp. 100-106, 2009.

[9] M. Behbahani-Nejad and A. Bagheri, "The accuracy and efficiency of a MATLAB-Simulink library for transient flow simulation of gas pipelines and networks," Journal of Petroleum Science and Engineering, vol. 70, no. 3-4, pp. 256-265, 2010.

[10] R. Alamian, M. Behbahani-Nejad, and A. Ghanbarzadeh, "A state space model for transient flow simulation in natural gas pipelines," Journal of Natural Gas Science and Engineering, vol. 9, pp. 51-59, 2012.

[11] M. Abbaspour and K. S. Chapman, "Nonisothermal transient flow in natural gas pipeline," Journal of Applied MechanicsTransactions ASME, vol. 75, no. 3, 2008.

[12] S.-S. Deng, S.-Q. Zhou, Z.-F. Liao, Z.-Y. Qiu, and S.-P. Zeng, "Theoretical analysis on hydraulic transient resulted by sudden increase of inlet pressure for laminar pipeline flow," Applied Mathematics and Mechanics, vol. 25, no. 6, pp. 672-678, 2004.

[13] W.-Y. Wan, S. Zhu, and Y.-J. Hu, "Attenuation analysis of hydraulic transients with laminar-turbulent flow alternations," Applied Mathematics and Mechanics-English Edition, vol. 31, no. 10, pp. 1209-1216, 2010.

[14] J.-S. Lee, B.-K. Kim, W.-R. Lee, and K.-Y. Oh, "Analysis of water hammer in pipelines by partial fraction expansion of transfer function in frequency domain," Journal of Mechanical Science and Technology, vol. 24, no. 10, pp. 1975-1980, 2010.

[15] E. Yao, G. Kember, and D. Hansen, "Analysis of water hammer attenuation in applications with varying valve closure times," Journal of Engineering Mechanics, vol. 141, no. 1, Article ID 04014107, 2015.

[16] X. Yu, J. Zhang, and D. Miao, "Innovative closure law for pump-turbines and field test verification," Journal of Hydraulic Engineering, vol. 141, no. 3, 2015.

[17] M. S. Ghidaoui, M. Zhao, D. A. McInnis, and D. H. Axworthy, "A review of water hammer theory and practice," Applied Mechanics Reviews, vol. 58, no. 1-6, pp. 49-75, 2005.

[18] E. B. Wylie and V. L. Streeter, Fluid Transients, McGraw-Hill, New York, NY, USA, 1978.

[19] D. Covas, I. Stoianov, J. F. Mano, H. Ramos, N. Graham, and C. Maksimovic, "The dynamic effect of pipe-wall viscoelasticity in hydraulic transients. Part I-experimental analysis and creep characterization," Journal of Hydraulic Research, vol. 42, no. 5, pp. 516-530, 2004.

[20] S. Evangelista, A. Leopardi, R. Pignatelli, and G. de Marinis, "Hydraulic transients in viscoelastic branched pipelines," Journal of Hydraulic Engineering, vol. 141, no. 8, 2015.

[21] H. Ramos, S. Tamminen, and D. Covas, "Water supply system performance for different pipe materials part II: sensitivity analysis to pressure variation," Water Resources Management, vol. 23, no. 2, pp. 367-393, 2009.

[22] A. K. Soares, D. I. C. Covas, and L. F. R. Reis, "Analysis of PVC pipe-wall viscoelasticity during water hammer," Journal of Hydraulic Engineering (ASCE), vol. 134, no. 9, pp. 1389-1394, 2008.

[23] C. Apollonio, D. I. C. Covas, G. de Marinis, A. Leopardi, and H. M. Ramos, "Creep functions for transients in HDPE pipes," Urban Water Journal, vol. 11, no. 2, pp. 160-166, 2014.

[24] C. Sun, S. S. Pang, Y. Zhao, and M. A. Stubblefield, Estimation of Water Hammer Speed in Composite Pipeline, Composite Materials: Design and Analysis, American Society of Mechanical Engineers, Petroleum Division Publication, 1998.

[25] I. S. Pearsall, "The velocity of water hammer waves," in Proceedings of the Institution of Mechanical Engineers, vol. 180, no. 5, pp. 12-20, SAGE, 1965.

[26] T. S. Lee and S. Pejovic, "Air influence on similarity of hydraulic transients and vibrations," Journal of Fluids Engineering, vol. 118, no. 4, pp. 706-709, 1996.

[27] F. E. Hachem and A. J. Schleiss, "Effect of drop in pipe wall stiffness on water-hammer speed and attenuation," Journal of Hydraulic Research, vol. 50, no. 2, pp. 218-227, 2012.

[28] W. Han, Z. Dong, and H. Chai, "Water hammer in pipelines with hyperconcentrated slurry flows carrying solid particles," Science in China, Series E: Technological Sciences, vol. 41, no. 4, pp. 337347, 1998.

[29] Y.-L. Zhou, B. Sun, X.-N. Duan, W.-P. Hong, and L. Zhang, "The calculation of slurry water hammer on liquid-solid twophase flow in complex pipeline systems," Journal of Engineering Thermophysics, vol. 25, no. 2, pp. 251-254, 2004.

[30] E. Hadj-Taïeb and T. Lili, "Validation of hyperbolic model for water-hammer in deformable pipes," Journal of Fluids Engineering, vol. 122, no. 1, pp. 57-64, 2000.

[31] K. Ando, T. Sanada, K. Inaba et al., "Shock propagation through a bubbly liquid in a deformable tube," Journal of Fluid Mechanics, vol. 671, pp. 339-363, 2011.

[32] M. Mitosek, "Study of transient vapor cavitation in series pipe systems," Journal of Hydraulic Engineering (ASCE), vol. 126, no. 12, pp. 904-911, 2000.

[33] D. Covas, I. Stoianov, H. Ramos, N. Graham, Č. Maksimović, and D. Butler, "Water hammer in pressurized polyethylene pipes: conceptual model and experimental analysis," Urban Water Journal, vol. 1, no. 2, pp. 177-197, 2004.

[34] D. Covas, I. Stoianov, J. F. Mano, H. Ramos, N. Graham, and C. Maksimovic, "The dynamic effect of pipe-wall viscoelasticity in hydraulic transients. Part II-model development, calibration and verification," Journal of Hydraulic Research, vol. 43, no. 1, pp. 56-70, 2005.

[35] J. H. Aklonis, W. J. MacKnight, M. Shen, and W. P. Mason, Introduction to Polymer Viscoelasticity, Wiley-Interscience, New York, NY, USA, 1972. 


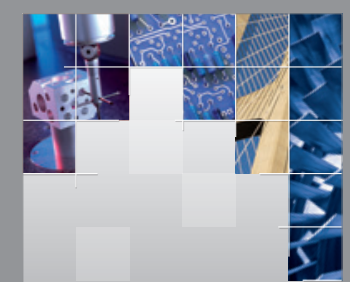

\section{Enfincering}
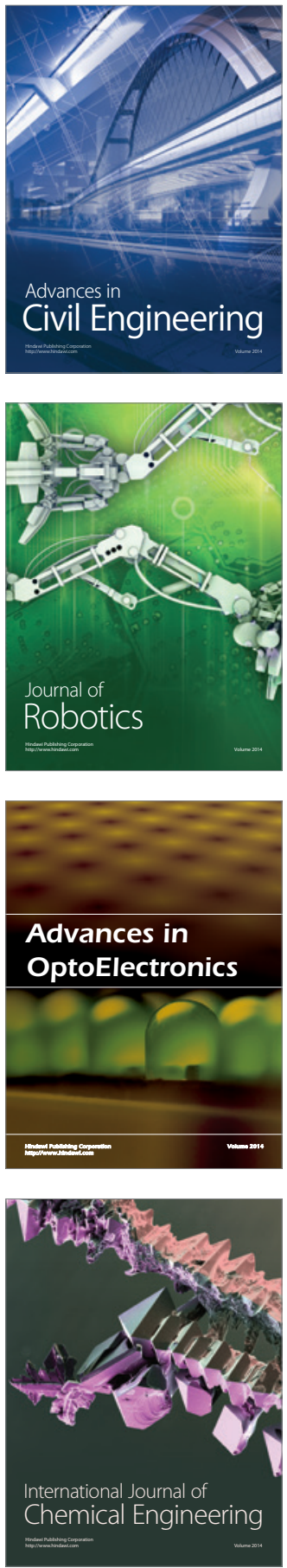

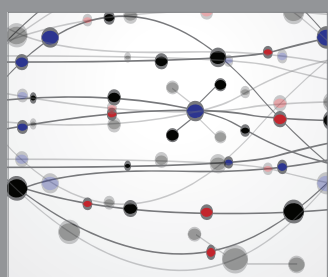

The Scientific World Journal

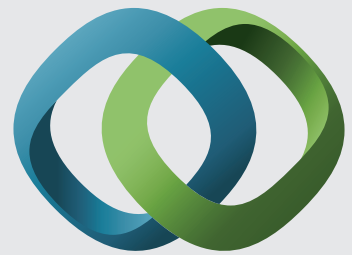

\section{Hindawi}

Submit your manuscripts at

http://www.hindawi.com
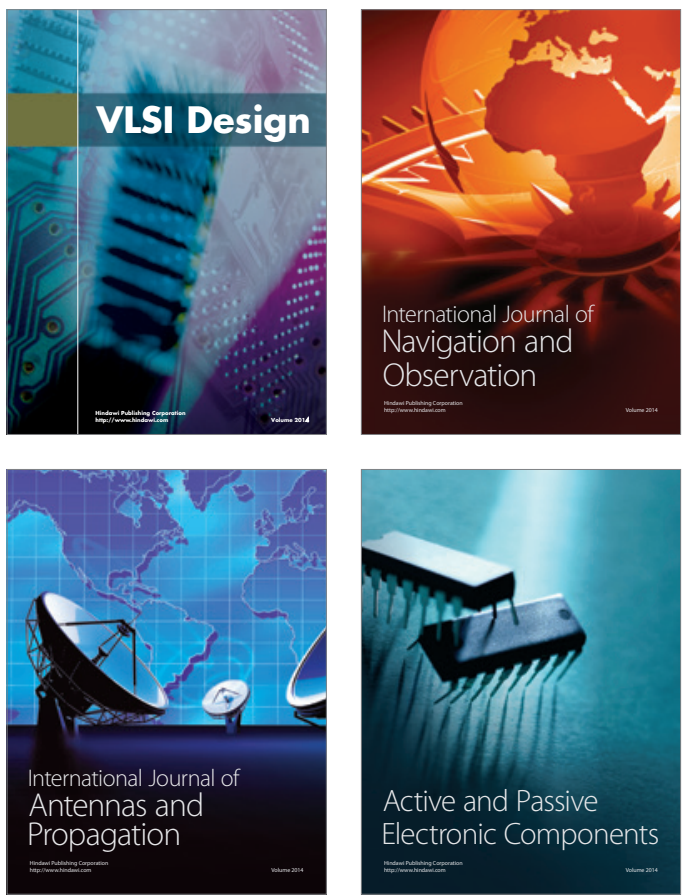
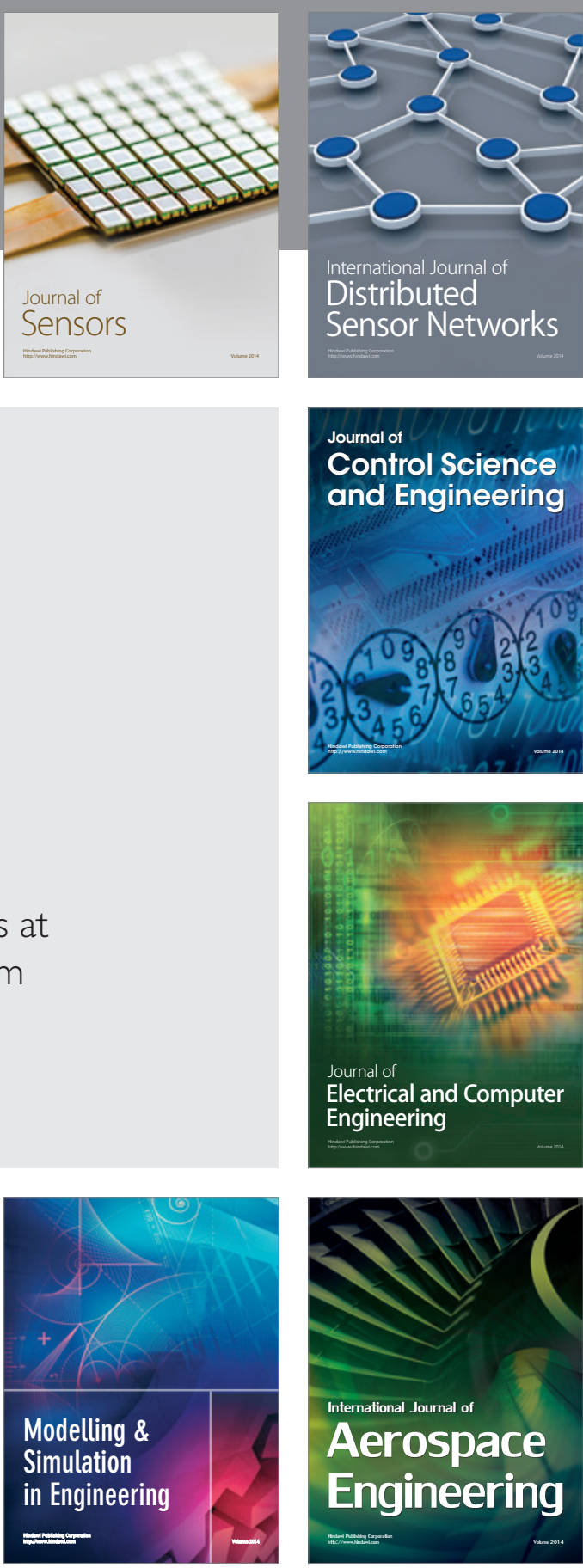

International Journal of

Distributed

Sensor Networks

Journal of

Control Science

and Engineering
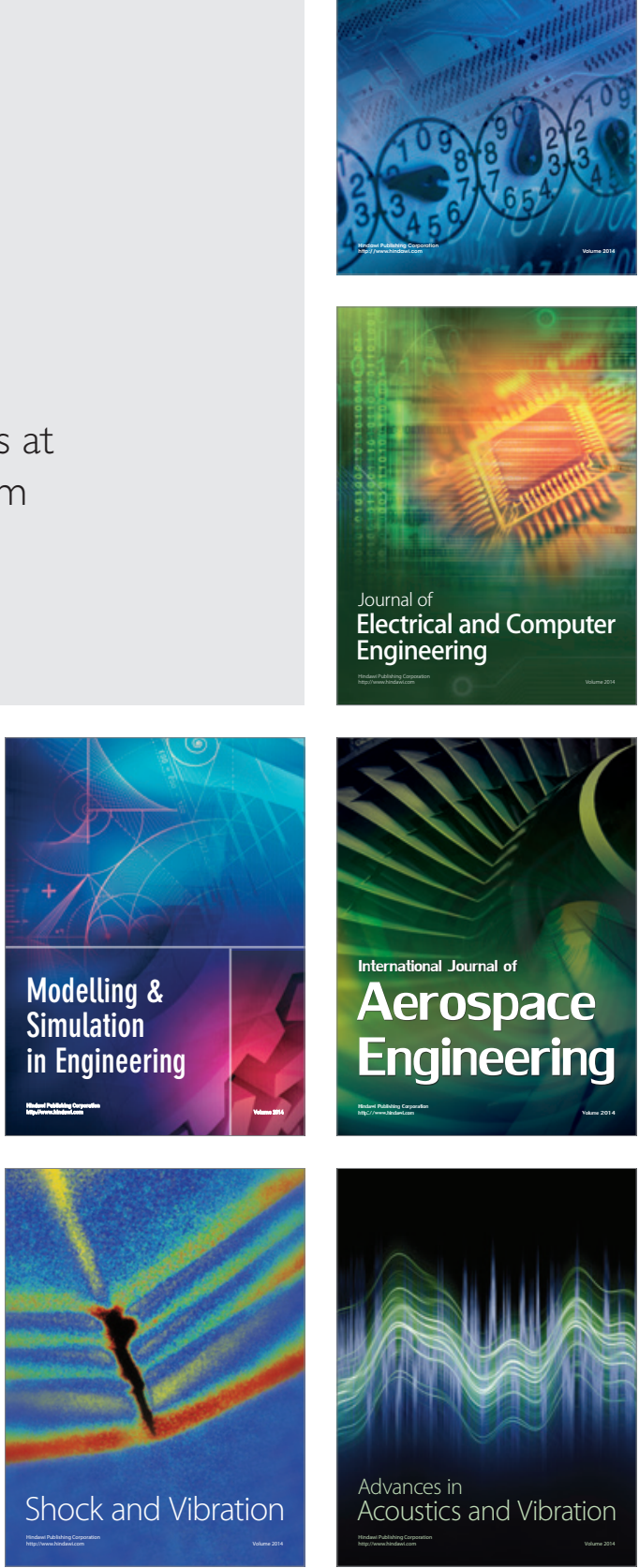